\title{
Reduced Motivation in Perinatal Fluoxetine-Treated Mice: A Hypodopaminergic Phenotype
}

\author{
Edênia C. Menezes, ${ }^{1}$ Relish Shah, ${ }^{1}$ Lindsay Laughlin, ${ }^{1}$ K. Yaragudri Vinod, ${ }^{1,2,3}$ John F. Smiley, ${ }^{1,3}$ \\ Catarina Cunha, ${ }^{1,3}$ Andrea Balla, ${ }^{4}$ Henry Sershen, ${ }^{4,5}$ Francisco X. Castellanos, ${ }^{1,3}$ André Corvelo, ${ }^{6}$ and \\ Cátia M. Teixeira ${ }^{1,3}$ \\ ${ }^{1}$ Emotional Brain Institute, Nathan Kline Institute for Psychiatric Research, Orangeburg, New York 10962, ${ }^{2}$ Department of Analytical \\ Psychopharmacology, Nathan Kline Institute for Psychiatric Research, Orangeburg, New York 10962, ${ }^{3}$ Department of Child and Adolescent \\ Psychiatry, New York University Grossman School of Medicine, New York, New York 10016, ${ }^{4}$ Department of Neurochemistry, Nathan Kline \\ Institute for Psychiatric Research, Orangeburg, New York 10962, ${ }^{5}$ Department of Psychiatry, New York University School of Medicine, New York, \\ New York 10016, and ${ }^{6}$ New York Genome Center, New York, New York 10013
}

Early life is a sensitive period, in which enhanced neural plasticity allows the developing brain to adapt to its environment. This plasticity can also be a risk factor in which maladaptive development can lead to long-lasting behavioral deficits. Here, we test how early-life exposure to the selective-serotonin-reuptake-inhibitor (SSRI), fluoxetine, affects motivation, and dopaminergic signaling in adulthood. We show for the first time that mice exposed to fluoxetine in the early postnatal period exhibit a reduction in effort-related motivation. These mice also show blunted responses to amphetamine and reduced dopaminergic activation in a sucrose reward task. Interestingly, we find that the reduction in motivation can be rescued in the adult by administering bupropion, a dopamine-norepinephrine reuptake inhibitor used as an antidepressant and a smoke cessation aid but not by fluoxetine. Taken together, our studies highlight the effects of early postnatal exposure of fluoxetine on motivation and demonstrate the involvement of the dopaminergic system in this process.

Key words: dopamine; fluoxetine; gestation; motivation; postnatal; serotonin

\section{Significance Statement}

The developmental period is characterized by enhanced plasticity. During this period, environmental factors have the potential to lead to enduring behavioral changes. Here, we show that exposure to the SSRI fluoxetine during a restricted period in early life leads to a reduction in adult motivation. We further show that this reduction is associated with decreased dopaminergic responsivity. Finally, we show that motivational deficits induced by early-life fluoxetine exposure can be rescued by adult administration of bupropion but not by fluoxetine.

\section{Introduction}

Multiple environmental factors can change serotonin levels during development, including stress (Papaioannou et al., 2002), physical abuse (Raineki et al., 2015; Rincón-Cortés et al., 2015), nutrition (Serfaty et al., 2008), genetic variants (Murphy et al., 2008), maternal inflammation (Goeden et al., 2016), and recreational and pharmaceutical drugs such as selective-serotoninreuptake-inhibitors (SSRIs; Xu et al., 2004; Suri et al., 2015). Risk factors for increased serotonin levels during development, e.g.,

Received Oct. 8, 2020; revised Jan. 26, 2021; accepted Jan. 29, 2021.

Author contributions: C.M.T. designed research; E.C.M., R.S., L.L., K.Y.V., J.F.S., A.B., H.S., A.C., and C.M.T. performed research; A.C. contributed unpublished reagents/analytic tools; E.C.M., L.L., A.B., H.S., F.X.C., and C.M.T. analyzed data; C.C. and C.M.T. wrote the paper.

This work was supported by National Institute of Child Health and Human Development Grants R01 HD095966 and R03 HD094978 (to C.M.T.). We thank Tom Davidson and Erin Calipari for assistance setting up the fiberphotometry equipment.

The authors declare no competing financial interests.

Correspondence should be addressed to Catia M. Teixeira at catia.teixeira@nki.rfmh.org.

https://doi.org/10.1523/JNEUROSCI.2608-20.2021

Copyright $\odot 2021$ the authors maternal inflammation and gestational SSRIs (used by $\sim 2-5 \%$ of women in the western world during pregnancy; Cooper et al., 2007; Huybrechts et al., 2013; Ramsteijn et al., 2020) are highly prevalent. Studies in rodents have shown that administration of some SSRIs prenatally or in the early postpartum period are linked to behavioral deficits in adult progeny (Ansorge et al., 2008; Rebello et al., 2014; Weinstock, 2015; Ramsteijn et al., 2020). These effects could reflect that this is a peak period for serotonergic development (Suri et al., 2015), which might make it more vulnerable to serotonin level modulations (Weinstock, 2015). In contrast, some studies have found positive effects of early life exposure to specific SSRIs (Altieri et al., 2015), notably a rescue in deficits caused by maternal depression (Velasquez et al., 2019). Of concern, some studies have implicated gestational exposure to SSRIs in the development of psychiatric disorders in humans (Malm et al., 2016; Singal et al., 2020). However, the mechanisms by which the administration of specific SSRIs in early life might affect adult behavior are mostly unknown. 
In rodents, serotonergic neurons emerge on embryonic day (E)12 (Lauder and Bloom, 1974) and start releasing serotonin at E13 (Lidov and Molliver, 1982a,b). Serotonin tissue levels peak in the first postnatal week, declining to adult levels by postnatal day (P) 15 (Hohmann et al., 1988). By comparison, the dopaminergic system develops more slowly, reaching adult levels only after adolescence. Dopaminergic neurons emerge between E12 and E15 (Olson and Seiger, 1972), but dopaminergic innervation can increase in some brain regions until P60 (Kalsbeek et al., 1988). In humans, birth is equivalent to P12-P13 in rodents in terms of brain serotonergic development (Homberg et al., 2010). Interestingly, recent work uncovered a robust disynaptic circuit linking the dorsal raphe (DR), ventral tegmental area (VTA), and nucleus accumbens (NAc; Beier et al., 2015). We hypothesize that the earlier developing serotonergic system sending projections to the dopaminergic system enables it to modulate dopaminergic development.

The dopaminergic system modulates multiple aspects of motivated behavior, specifically effort-related behaviors (Correa et al., 2016; Robinson et al., 2016; Salamone et al., 2016b). We have recently shown that early life fluoxetine exposure leads to deficits in serotonergic activation of dopaminergic neurons, mediated by impaired glutamatergic co-transmission (Cunha et al., 2020). We hypothesized that high levels of serotonin during development impair dopaminergic function, causing dopaminedependent behavioral changes. Here, our novel findings show that early postnatal exposure to the SSRI fluoxetine (PN-fluoxetine) leads to deficits in motivation. Treated animals showed deficits in motivated responses in a progressive ratio (PR) schedule of reinforcement during operant conditioning while exhibiting close to typical performance at lower response ratios, in keeping with the greater influence of the dopaminergic system in more effortful conditions (Correa et al., 2016; Robinson et al., 2016; Salamone et al., 2016b). Supporting our hypothesis that high serotonin levels during early life affect dopaminergic function, we found that PN-fluoxetine-treated animals had a blunted dopaminergic response to sucrose, measured by fiber photometry, and reduced increase in dopamine, measured by microdialysis after an amphetamine challenge. Furthermore, we show that motivation reduction in $\mathrm{PN}$-fluoxetine-treated mice can be rescued in the adult by bupropion (a norepinephrine-dopamine reuptake inhibitor, strongly acting on the dopaminergic system; Horst and Preskorn, 1998) but not by the SSRI fluoxetine.

\section{Materials and Methods}

Subjects

Experiments were performed at the Nathan Kline Institute for Psychiatric Research (NKI). Experiments were conducted blind, using only an ear tag number as an identifier during experiments, in compliance with the Principles of Laboratory Animal Care National Institutes of Health guidelines, and under protocols approved by NKI. Mice were housed in groups (two to four mice of same-sex per cage) and maintained on a $12 / 12 \mathrm{~h}$ light/dark cycle with access to food and water ad libitum. Approximately equal numbers of male and female mice were used in the experiments, except in the adult rescue experiment for which we only used males, as the females in that batch had been used in another project. Mice were tested as adults, between three and five months of age. We used mice on a C57BL/6J background (except for experiments in Fig. 3, for which the mice were on a 129SvEv/Tac background).

\section{Postnatal fluoxetine treatment}

P2 pups were randomly assigned to saline (vehicle) or $10 \mathrm{mg} / \mathrm{kg}$ fluoxetine. The mice received daily intraperitoneal injections of the assigned treatment from P2 to P11, as previously described (Rebello et al., 2014).
We previously found that $\mathrm{PN}$-saline animals do not differ from naive ones in a novelty-induced hypophagia test (a sucrose consumption test performed in a new large arena, a rat-sized cage), while $\mathrm{PN}$-fluoxetine animals consumed significantly less sucrose $\left(t_{(46)}=2.171, p=0.04\right.$; Fig. $1 A, B)$, suggesting that the injections alone do not produce an anxietylike phenotype. We, therefore, use saline-injected mice as controls throughout. We administered drug treatments between P2 and P11 because it is a time window previously identified as a critical period in which fluoxetine administration is sufficient to produce behavioral deficits in the adult which are not obtainable after this time window (Rebello et al., 2014). In terms of the developing serotonergic system, the first postnatal weeks in rodents correspond to the third trimester of pregnancy in humans (Homberg et al., 2010; Suri et al., 2015).

\section{Behavioral testing}

All mice were habituated to drink a $20 \%$ sucrose solution in their home cage for a week. Mice were trained in acrylic conditioning chambers containing two nose-poke holes and a reward hole. The chambers were designed in-house based on the open-source Arduino microcontroller platform adapted from (Devarakonda et al., 2016). Mice were food restricted to maintain $85-90 \%$ of their initial weight. Pokes in the "active hole" deliver a $20 \%$ reward sucrose solution in the reward port, while pokes in the "inactive hole" are unrewarded. We performed a standard operant conditioning procedure in which mice progressed from a fixed ratio (FR)1 to an FR5 ratio (FR1: one correct poke= one reward; FR5: five pokes in the active hole are needed to obtain one reward) and were then tested in a PR schedule (mice need to make an increasingly higher number of correct nose-pokes to receive a reward following a progression ratio of $r=5 \mathrm{e}^{0.2 \mathrm{n}}-5$ ) as previously described in (Devarakonda et al., 2016). Mice were trained daily, for $45 \mathrm{~min}$, on the FR1 program until they met acquisition criteria by earning $>20$ sucrose deliveries in a session and exhibiting discrimination $>3: 1$ for the active versus inactive nose pokes. Once mice met acquisition FR1 criteria for three consecutive days, they were trained on the FR5 reinforcement schedule for $3 \mathrm{~d}$, $45 \mathrm{~min} / \mathrm{d}$, followed by the PR reinforcement schedule. We assessed the break point for the PR sessions; that is, the maximum number of pokes a mouse would perform to receive a reward (highest ratio completed). Each PR session ended when $1 \mathrm{~h}$ had elapsed. This measure was used as an index of motivation.

In experiment $1, \mathrm{PR}$ response was tested in naive mice $1 \mathrm{~h}$ after an intraperitoneal injection of either saline (vehicle for bupropion), bupropion (40 mg/kg; Randall et al., 2014), 0.3\% tartaric acid in PBS (vehicle for haloperidol), or haloperidol $(0.1 \mathrm{mg} / \mathrm{kg})$, in counterbalanced order, with treatments spaced apart by $72 \mathrm{~h}$. The haloperidol dose and dilution procedure were as described previously (Yang et al., 2020). In between treatments, mice were trained on the FR5 schedule. After completing all $\mathrm{PR}$ testing sessions, mice were tested for their response on FR1 for $1 \mathrm{~h}$ following the same drug treatments, in counterbalanced order, with treatments spaced apart by $72 \mathrm{~h}$. In experiment 2 , performance was compared between $\mathrm{PN}$-saline-treated and $\mathrm{PN}$-fluoxetine-treated mice. In experiment 3, the PR response of PN-treated mice was tested $1 \mathrm{~h}$ after an intraperitoneal injection of saline (vehicle), fluoxetine $(10 \mathrm{mg} / \mathrm{kg})$, or bupropion $(40 \mathrm{mg} / \mathrm{kg}$ ). All mice were tested with the three treatments, in counterbalanced order, with treatments spaced apart by $72 \mathrm{~h}$. Counterbalancing included pseudo-randomization so that in each trial, an equal number of mice was assigned to each treatment.

\section{Amphetamine challenge in the open-field}

Activity was measured as ambulatory counts (interruption of a total number of both $x$ - and $y$-axes beams) with an infrared beam-based activity sensor (ATM3; Columbus Instruments) over $60 \mathrm{~min}$ as described previously (Sershen et al., 2010). Saline or amphetamine (3 mg/kg, i.p.; Yu et al., 2014) were administered $20 \mathrm{~min}$ after the test began.

Amphetamine challenge and microdialysis

A separate cohort of adult mice, PN-treated with fluoxetine or saline as described above, was implanted with microdialysis guide cannulas in the striatum (AP: $0.7 \mathrm{~mm}, \mathrm{~L}: 1.5 \mathrm{~mm}, \mathrm{DV}:-2.5 \mathrm{~mm}$ ). Animals were allowed to recover one week before the microdialysis experiment, conducted in 
A

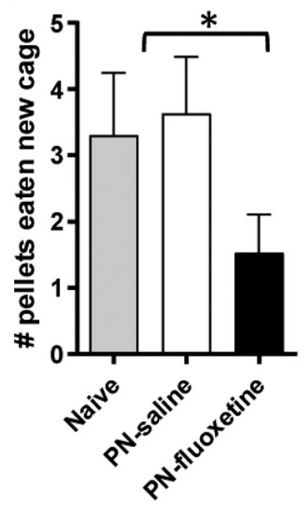

B

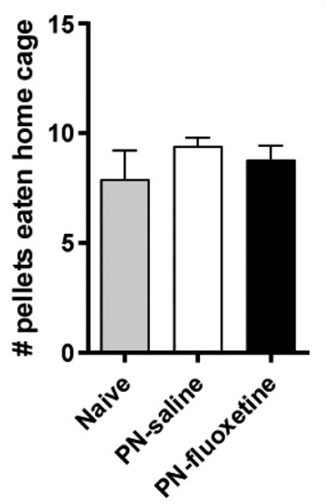

C

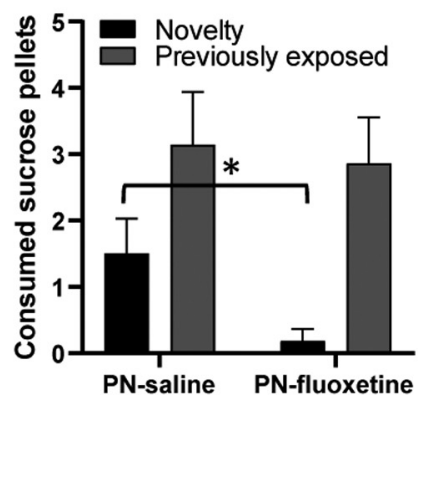

Figure 1. Novelty induced hypophagia. $\boldsymbol{A}$, Naive, PN-saline-treated, and PN-fluoxetine-treated mice were food deprived overnight. The next day, they were placed for 30 min in a large arena (a standard rat cage) with a Petri dish containing 20 sucrose pellets. The number of pellets consumed was counted. PN-fluoxetine-treated animals ate fewer pellets than naive/saline control animals. B, Naive and PN-treated mice were food deprived overnight and given a Petri dish containing 20 sucrose pellets in their home cage. All groups consumed approximately the same number of pellets in $30 \mathrm{~min}(n=10-19)$. C, Non-food-deprived mice were placed in a large arena containing a Petri dish with 20 sucrose pellets for 30 min. PN-fluoxetine-treated mice consumed less of this novel food than PN-saline-treated animals. The same group of animals were food deprived and given only sucrose pellets to eat for a day. The mice were then returned to their normal diet. PN-fluoxetine and PN-saline mice, non-food-deprived, consumed the same amount of sucrose pellets when presented again with this food ( $n=14-22)$. Data are expressed as the mean $\pm \mathrm{SEM} ; * p<0.05$.
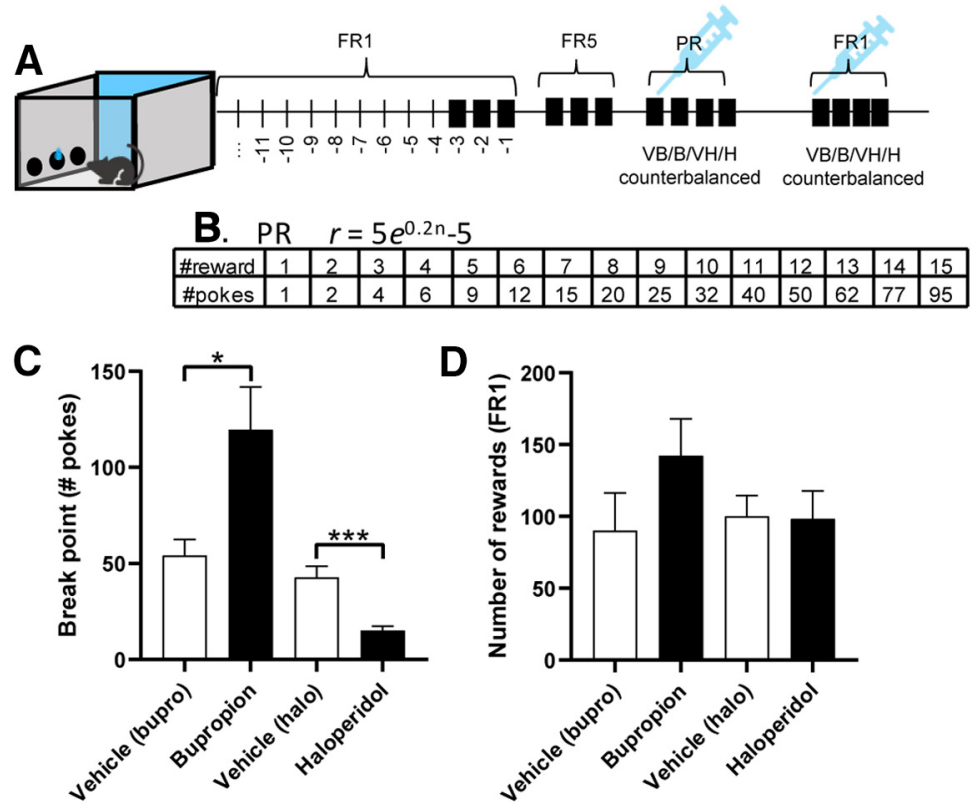

Figure 2. Dopamine's role in effort-related motivation. $A$, Experimental design. Mice were trained on a FR1 schedule of reinforcement until reaching criteria for three consecutive days. They were then trained for an additional $3 \mathrm{~d}$ on the FR5 schedule. The following day, they were tested on the PR $1 \mathrm{~h}$ after receiving an injection of either saline-bupropion vehicle (VB), bupropion (B), haloperidol-vehicle (VH), or haloperidol (H). Treatments were repeated counterbalanced with 3-d intervals. After testing in PR, mice were tested in FR1 in response to the same drug treatments in counterbalanced order. $\boldsymbol{B}$, Progression on the PR. $\boldsymbol{C}$, Break point on PR schedule after adult treatment $(n=19$ repeated measures). $\boldsymbol{D}$, Sucrose rewards during FR1. Data are expressed as the mean $\pm \mathrm{SEM} ; * p<0.05, * * * p<0.001$.

awake, freely moving mice using a BAS microdialysis cage system (BASi). On the day of the experiment, microdialysis probes (CMA-7 probe, CMA/Microdialysis) were inserted into the guide cannula. A 2$\mathrm{mm}$ membrane length probe was inserted via the guide cannula targeting the striatum. As the membranes are $2 \mathrm{~mm}$ long, we could not precisely target the NAc and therefore collected samples across the dorsoventral striatum. Probes were perfused with CNS perfusion fluid (M Dialysis $\mathrm{AB}$ ) at a flow rate of $1.5 \mu \mathrm{l} / \mathrm{min}$. After a 1 -h equilibration period, baseline samples ( $30 \mathrm{~min}$ each) were collected for $2 \mathrm{~h}$. Next, we performed an amphetamine challenge ( $3 \mathrm{mg} / \mathrm{kg}$, i.p.). Thirty-minute samples continued to be collected for $3 \mathrm{~h}$. Dopamine and its metabolites were measured by electrochemical detection (HPLC-EC) using an ESA CoulArray Detector ESA Inc. as described previously (Balla et al., 2018). We compared the area under the curve for dopamine levels prior to and postamphetamine injection as previously described (Shen et al., 2004).

\section{Fiber-photometry}

To target GCAMP6 expression to dopaminergic neurons, a mouse line that specifically expresses Cre in dopaminergic cells (Dat-IRES-Cre; Bäckman et al., 2006) was crossed with one that conditionally expresses GCamp6 (Jax line ai95; Madisen et al., 2015) on a C57BL/6J background. We chose to use transgenic animals instead of a viral vector because the former allows for more consistent labeling of the entire dopaminergic population, reducing interindividual variability, allowing better comparisons between PN treatments. To confirm the specificity of GCamp6 expression in dopamine cells, two adult $\mathrm{Dat}^{\mathrm{IRES}-\mathrm{Cre} /+} ;$ GCAMP6 $^{\mathrm{fl} / \mathrm{fl}}$ (Dat-GCAMP6) mice were processed for double-label immunofluorescence using methods described in our previous study (Cunha et al., 2020). GCamp6 was identified using chicken anti-green fluorescent protein (GFP; Abcam, ab13970) coupled to Alex Fluor 488 secondary antibody (Invitrogen, A11034) and dopamine cells with rabbit anti-tyrosine hydroxylase (TH; Pelfreez, P40101) coupled to a biotinylated antibody (Vectastain, BA-1000) and streptavidin594 (Invitrogen, S11227). Immunolabeled cells were stereologically sampled using the fractionator method (Gundersen et al., 1988). Every fourth $50-\mu \mathrm{m}$-thick coronal section through the full extent of the VTA was sampled with a grid of optical dissectors, so that six to seven sections and 661-782 immunolabeled cells were evaluated in each brain.

Dat-GCAMP6 mice were administered fluoxetine or saline between P2 and P11 as described above. Adult animals were implanted with fiber-optic probes $(400 \mathrm{~nm})$ targeting the VTA (AP: $-3.5 \mathrm{~mm}, \mathrm{~L}: 0.5$ $\mathrm{mm}, \mathrm{DV}:-4.3 \mathrm{~mm}$ ). It is important to note that GCaMP6 is expected to express in all DAT + neurons in the brain, not exclusively in VTA ones. Therefore, DAT+ cells located elsewhere may project to or through 


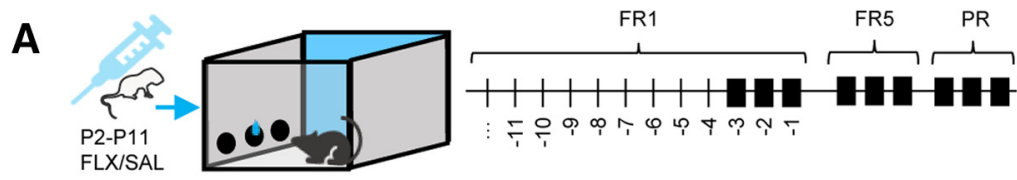

B
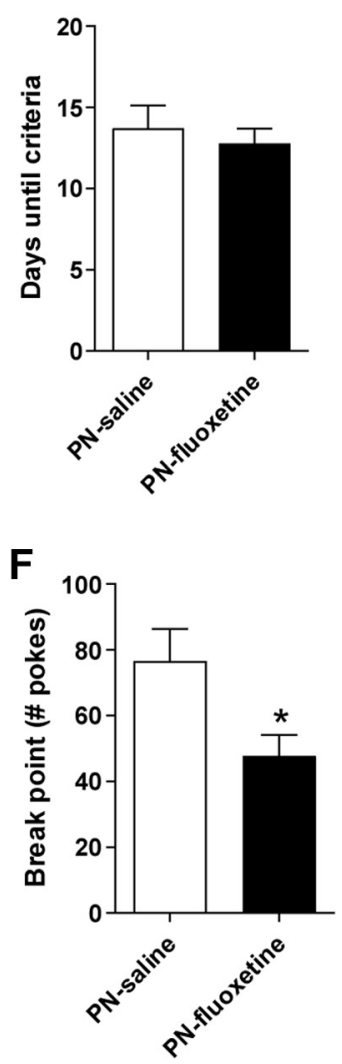

C

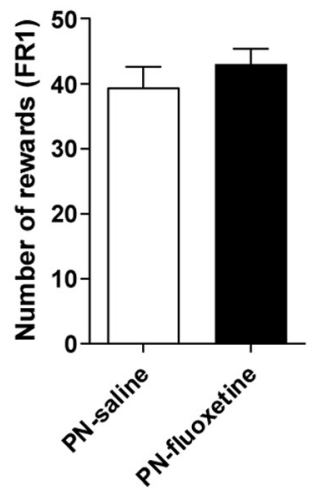

G

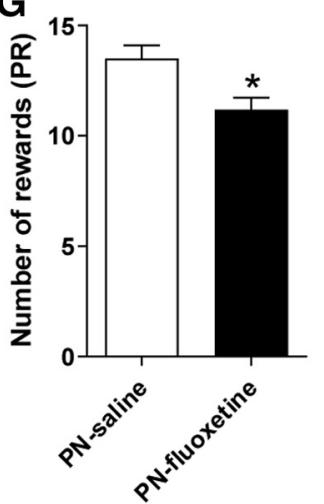

E

D

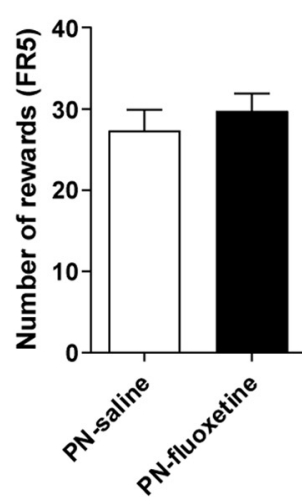

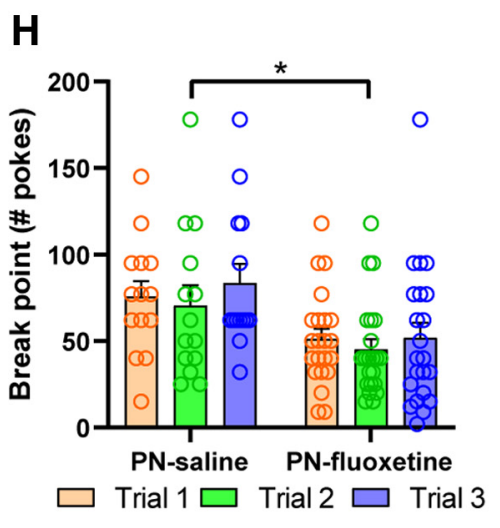

Figure 3. PN-fluoxetine treatment impairs effort-related motivation. $\boldsymbol{A}$, Experimental design. PN-treated mice (FLX, fluoxetine; SAL, saline) were trained on a FR1 schedule of reinforcement until reaching criteria. They were then trained for an additional $3 \mathrm{~d}$ on the FR5 schedule. The following day, they were tested on the PR for $3 \mathrm{~d}$. $\boldsymbol{B}$, Days until criteria. $\boldsymbol{C}$, Average number of rewards received on the last $3 \mathrm{~d}$ of FR1 training (in which they reached criteria). $\boldsymbol{D}$, Average number of rewards received on $3 \mathrm{~d}$ of FR5. $\boldsymbol{E}$, Average break point on PR schedule by sex. $\boldsymbol{F}$, Average break point on PR schedule for both sexes. $\mathbf{G}$, Average number of rewards obtained on PR schedule. $\boldsymbol{H}$, Break point on PR in each individual trial $\left(n_{\mathrm{PN} \text {-saline }}=14\right.$, $n_{\mathrm{PN} \text {-fluoxetine }}=22$ ). Data are expressed as the mean \pm SEM; $* p<0.05$.

VTA, thereby potentially contributing axonal signal to fiber photometry recordings made in VTA. After recovery, mice were habituated to drinking a $20 \%$ sucrose solution (the same concentration used in operant conditioning) for one week. The day before the sucrose test, they were water-deprived. On the test day, mice were connected to a laser emitter/ photoreceptor apparatus. Activity-dependent GCAMP6 fluorescence was recorded during a sucrose consumption test in a standard mouse cage, identical to the ones they were housed in, other than having a hole in the lid for the photometry cable. These procedures were performed to remove the effect of novelty, as we consistently found that PN-fluoxetine-treated animals show reduced consumption of new foods presented in novel environments (Sidak's multiple comparisons test Novelty:salineVSfluoxetine: adjusted $p=0.003$; Exposed:salineVSfluoxetine: adjusted $p=0.999$; Fig. $1 C$; Cunha et al., 2020). Our photometry apparatus includes a 405-nm LED channel as a control. To control for movement-related artifacts, we normalized $470-\mathrm{nm}$ signals to $405-\mathrm{nm}$ control fluorescence and calculated the fluorescence difference $(\mathrm{dF} /$ $\mathrm{F}_{\text {stimulus }}-\mathrm{dF} / \mathrm{F}_{\text {baseline }}$ ) as previously described (Kim et al., 2016). Data were acquired using TDT software and analyzed in Spike2. We used the variation in fluorescence between the $500 \mathrm{~ms}$ before and $500 \mathrm{~ms}$ after the first lick on the sucrose dispenser bottle for comparison between groups. Licking activity was time-stamped onto the photometry recording via a 5-ms TTL pulse from the touch-sensor (Anymaze) connected to the drinking spout.
Statistics

Results are presented as mean \pm SE. Statistical comparisons were conducted using Prism 8 (GraphPad), and differences between the groups were evaluated by unpaired, two-tailed Student's $t$ test, or ANOVA whenever appropriate. Normality before ANOVA was tested using the Shapiro-Wilk test. Statistical significance was set at $p<0.05$; $p$ values for multiple comparisons were corrected using Sidak's multiple comparisons test.

\section{Results}

Dopamine levels modulate the breaking point in the PR

Effort-related motivation has been linked to dopamine levels in adult animals (Salamone et al., 2016b). Many of these studies have been conducted in rats (Aberman et al., 1998; Randall et al., 2012; Randall et al., 2014), with more limited information in mouse models (Yang et al., 2020). Therefore, we tested how manipulating dopamine levels in the adult mouse would affect motivation in the PR schedule. We hypothesized that increasing dopaminergic signaling would increase effort-related responding, while decreasing it, by blocking dopamine type 2 receptors using haloperidol, would lead to decreased effort-related PR responding. 

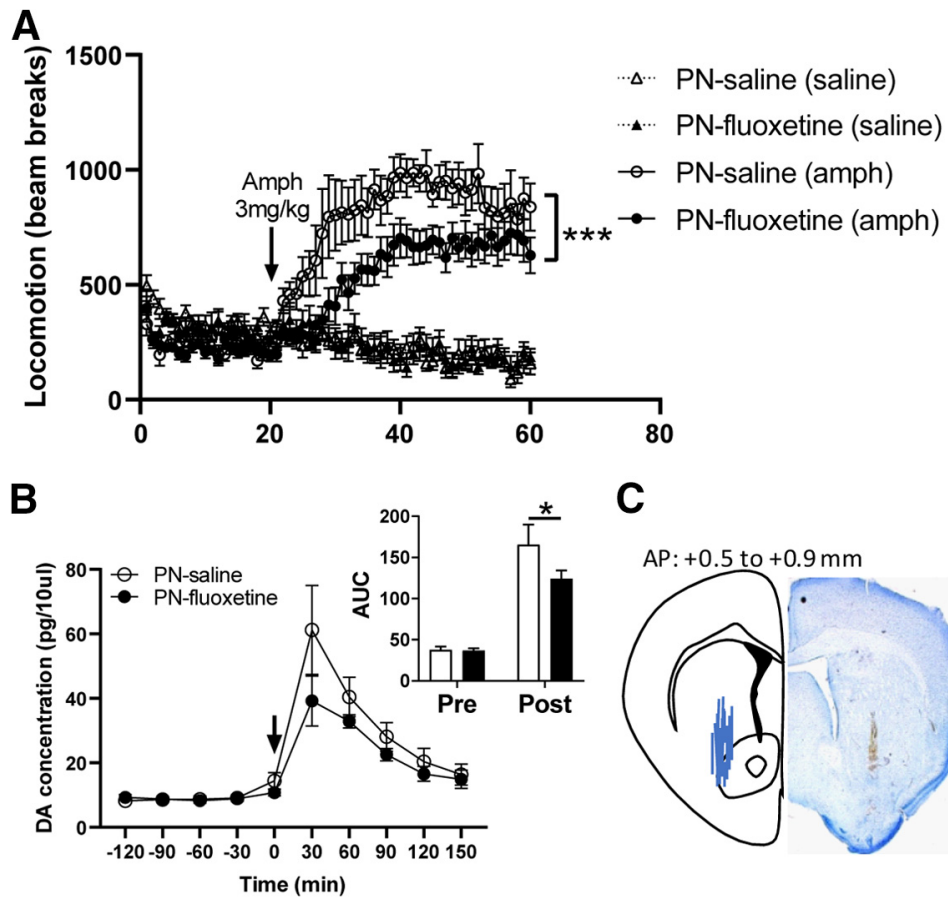

C

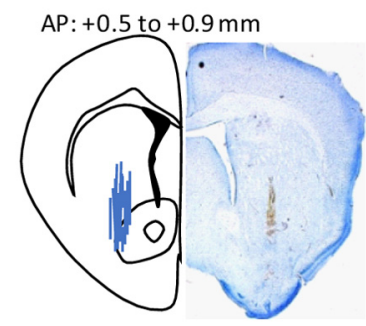

Figure 4. PN-fluoxetine treatment blunts amphetamine response. $\boldsymbol{A}, \mathrm{PN}$-treated mice were placed in an open-field and their locomotion was recorded in 1-min bins for a total of $60 \mathrm{~min} ; 20 \mathrm{~min}$ after the beginning of the experiments, mice were injected with saline or $3 \mathrm{mg} / \mathrm{kg}$ of amphetamine. We observed blunted hyperlocomotion in response to an amphetamine challenge in PN-fluoxetine-treated mice $\left(n_{\mathrm{PN}-\text { saline/saline }}=8, n_{\mathrm{PN} \text {-saline/amphetamine }}=7, n_{\mathrm{PN} \text {-fluoxetine/saline }}=\right.$ $8, n_{\mathrm{PN} \text {-fluoxetine/amphetamine }}=8$ ). $\boldsymbol{B}$, Microdialysis analysis of dopamine levels at baseline and after amphetamine challenge (arrow; $3 \mathrm{mg} / \mathrm{kg}$, i.p.). Top right inset, Area under the curve (AUC) for preamphetamine and postamphetamine injection $\left(n_{\mathrm{PN} \text {-saline }}=10, n_{\mathrm{PN} \text {-fluoxetine }}=10\right)$. C, Placements of microdialysis probes verified histologically. Data are expressed as the mean \pm SEM; $* p<0.05, * * * p<0.001$.

Naive mice were trained on FR1 until reaching criteria for three consecutive days. They were then trained for $3 \mathrm{~d}$ on FR5 and then tested on PR $1 \mathrm{~h}$ after an intraperitoneal injection of saline (vehicle for bupropion), bupropion $(40 \mathrm{mg} / \mathrm{kg}$; a norepinephrine-dopamine reuptake inhibitor; Randall et al., 2014), $0.3 \%$ tartaric acid in PBS (vehicle for haloperidol) or haloperidol $(0.1 \mathrm{mg} / \mathrm{kg}$; a dopamine receptor type 2 antagonist; Yang et al., 2020 ), in counterbalanced order (Fig. $2 A, B$ ). Consistent with previous studies (Randall et al., 2014; Yang et al., 2020), haloperidol decreased the PR break point $\left(F_{(1,22)}=15.80, p=0.0003\right.$; Sidak's multiple comparisons test ${ }_{\mathrm{VHvsH}}$ : adjusted $p=0.0002$; Fig. $2 C$ ) while bupropion increased it (Sidak's multiple comparisons test vBvsB: adjusted $p=0.01$; Fig. $2 C$ ). There were no significant differences between the two vehicles used (Sidak's multiple comparisons test ${ }_{\mathrm{VBvsVH}}$ : adjusted $p=0.31$ ). Haloperidol and bupropion did not change sucrose intake on the less effortful FR1 schedule $\left(F_{(1,35)}=1.956, p=0.16\right.$; Fig. $\left.2 D\right)$.

\section{PN-fluoxetine treatment led to effort-related motivation deficits}

PN-fluoxetine administration was shown to reduce exploration in several studies (Ansorge et al., 2004; Rebello et al., 2014). Consistently, mice lacking serotonin transporters (SERT-KO mice) have reductions in exploration and activity in noveltybased tests (Kalueff et al., 2007). Recently, we showed that an increase in serotonergic tone during development induced by fluoxetine results in dopaminergic dysfunction (Cunha et al., 2020). Given the role of dopamine in effort-related motivation (Correa et al., 2016; Robinson et al., 2016; Salamone et al., 2016b), we hypothesized that PN-fluoxetine treatment could cause deficits in motivation.

Mice were injected with saline or fluoxetine $(10 \mathrm{mg} / \mathrm{kg})$ daily from P2 to P11. To test effort-related motivation in adulthood, we used an operant conditioning task to change the effort required to obtain a sucrose reward (Fig. 3A).

Both groups of animals took the same time to reach criteria $\left(t_{(34)}=0.5900, p=0.56\right.$; Fig. 3B). Consistent with current theories of dopaminergic function in effort-based tasks (Salamone et al., 2016b), we found no significant differences between PN-fluoxetinetreated animals and $\mathrm{PN}$-saline controls on FR1 $\left(t_{(33)}=0.82, p=0.42\right.$; Fig. $\left.3 C\right)$ and FR5 reinforcement schedules $\left(t_{(33)}=0.62, p=0.54\right.$; Fig. $3 D$ ). However, when the effort to retrieve a reward increased in the $\mathrm{PR}, \mathrm{PN}$-fluoxetinetreated animals performed worse than $\mathrm{PN}$-saline-treated animals (Fig. $3 E-H$ ). We found no significant sex differences, nor a sex by treatment interaction (sex $\times \mathrm{PN}$ treatment: $F_{(1,31)}=0.6525, p=0.43$; sex: $F_{(1,31)}=0.5128$, $p=0.48 ; \quad$ PN treatment: $F_{(1,31)}=5.511$, $p=0.03$; Fig. $3 E$ ), we therefore combined the data from both sexes for further analysis. The combined break point was lower in PN-fluoxetine-treated animals $\left(t_{(33)}=2.60, p=0.01\right.$; Fig. $3 F)$, as was the number of rewards obtained in the PR $\left(t_{(33)}=2.736, p=0.01\right.$; Fig. $3 G)$. Moreover, there was no effect of trial in the response (trial $\times$ PN treatment: $F_{(2,102)}=$ $0.1038, p=0.90$; trial: $F_{(2,102)}=0.6710, p=$ 0.51 ; PN treatment: $F_{(1,102)}=15.00, p=0.0002$; Fig. $\left.3 H\right)$.

\section{PN-fluoxetine treatment leads to blunted hyperlocomotion and dopamine release after an amphetamine challenge} To examine the function of the dopaminergic system, PN-fluoxetine-exposed mice were tested for their response to an amphetamine challenge in the open-field, and their striatal dopamine levels were measured using microdialysis.

$\mathrm{PN}$-saline and PN-fluoxetine animals were placed in an open field for $20 \mathrm{~min}$, and their locomotion was recorded. After this 20 -min baseline, the animals were injected with $3 \mathrm{mg} / \mathrm{kg}$ amphetamine or saline, and their locomotion was recorded for an additional $40 \mathrm{~min}$. We observed that after the amphetamine injection, PN-saline-treated animals had significantly higher locomotion levels than $\mathrm{PN}$-fluoxetine-treated animals [time $\times$ treatment: $F_{(177,1829)}=11.95, p<0.0001$; Tukey PN-saline (amph) vs PNfluoxetine (amph): adjusted $p<0.0001$; Fig. $4 A$ ].

To assess the effect of PN-fluoxetine exposure on dopamine release, microdialysis was performed in mice $\mathrm{PN}$-treated with saline or fluoxetine. Using the calculation of the area under the time-response curves (Fig. $4 B$, inset), as previously described (Shen et al., 2004), no difference in baseline dopamine levels was found in fluoxetine treated mice compared with the saline group (pre-amph, Fig. $4 B$; multiple comparisons: $t$ ratio $(36)=0.055$; adjusted $p=0.957)$. Next, mice were injected with $3 \mathrm{mg} / \mathrm{kg}$ amphetamine. A significantly lower dopamine level was observed in PN-fluoxetine-treated animals than in the control group ( $t$ ratio $_{(36)}=2.179$; adjusted $p=0.04$; Fig. $4 B$ ), suggesting a blunted dopaminergic response in $\mathrm{PN}$-fluoxetine-treated animals. The 
A

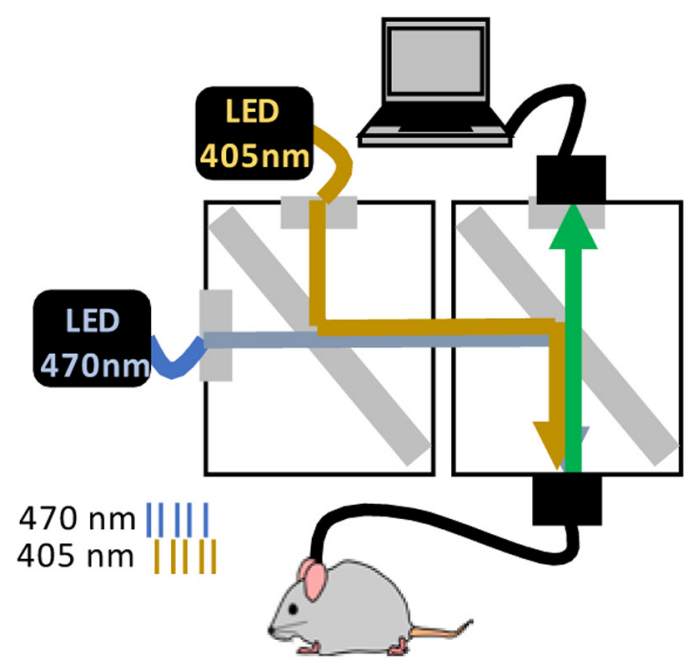

B

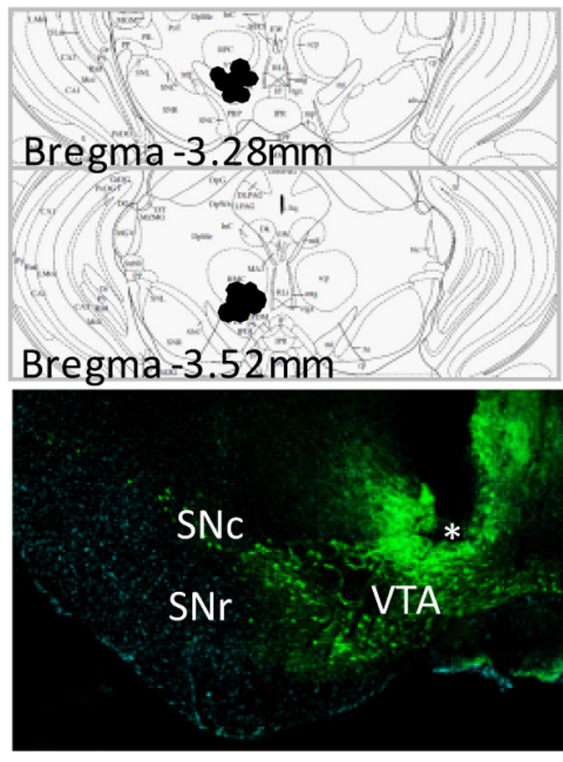

C
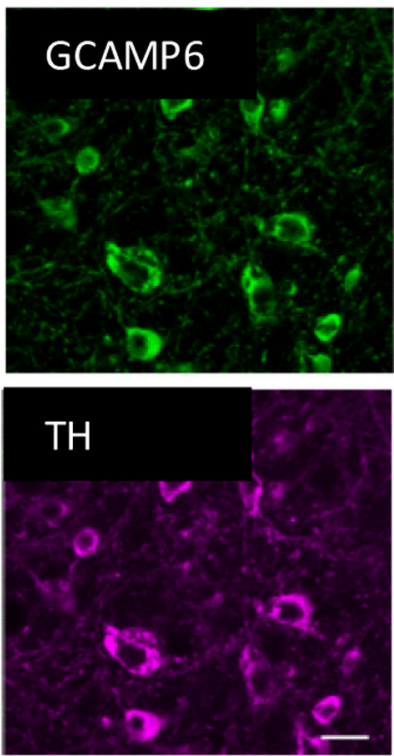
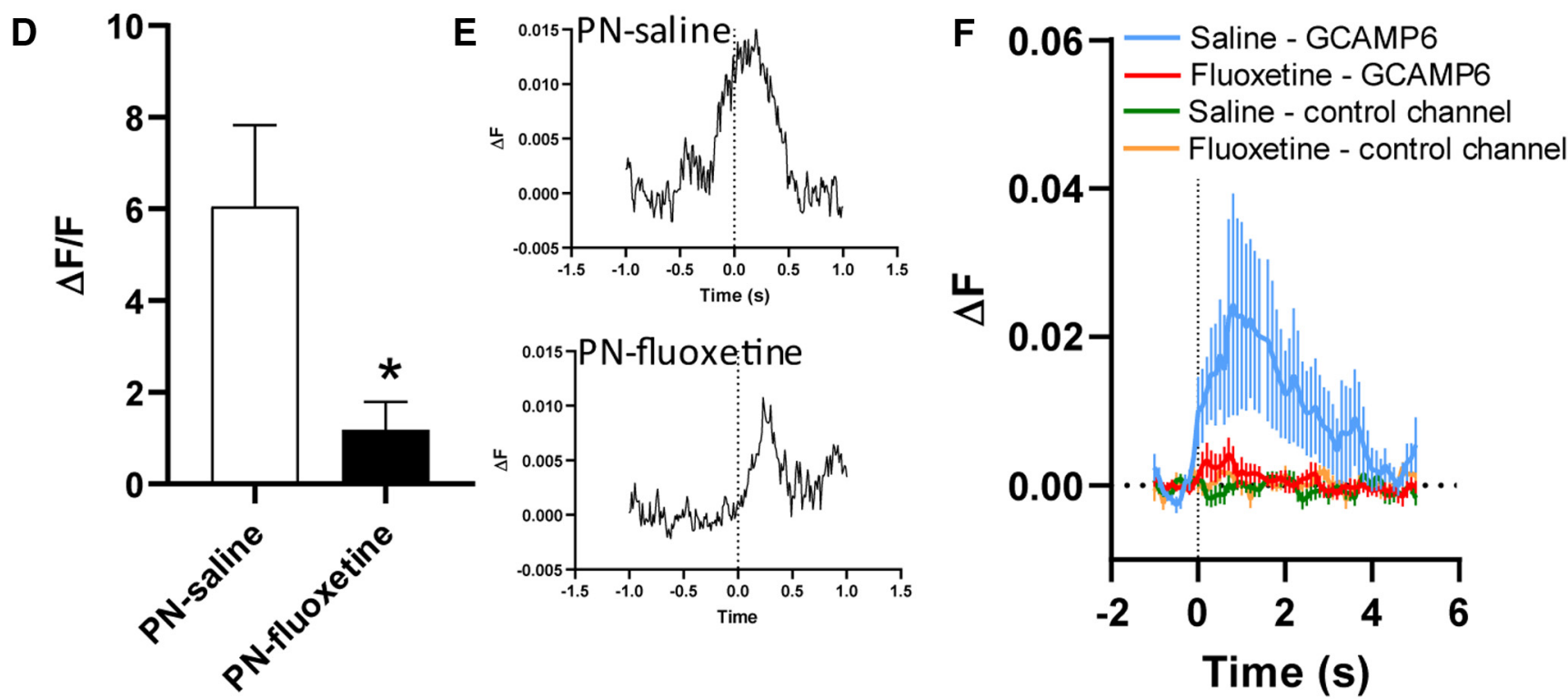

Figure 5. PN-fluoxetine treatment blunts dopaminergic response to sucrose. $\boldsymbol{A}$, Scheme of photometry apparatus with 405 -nm control channel and 470 -nm GCamp6 activity recording channel. $\boldsymbol{B}$, Placement of the optic fiber probe tips. $\boldsymbol{C}$, TH colocalization with GCamp6 + cells. $\boldsymbol{D}$, There was a significantly higher increase in fluorescence during sucrose consumption in PN-saline animals than in PN-fluoxetine animals ( $n_{\mathrm{PN} \text {-saline }}=11, n_{\mathrm{PN} \text {-fluoxetine }}=7$ ). $\boldsymbol{E}$, Individual recordings of a PN-saline (top) and PN-fluoxetine (bottom) animal. Time 0 marks the first lick. $\boldsymbol{F}$, Subject averaged traces. Data are expressed as the mean \pm SEM; $* p<0.05$.

placements of microdialysis probes were verified histologically. A representative image with probe placement is shown in Figure $4 C$.

\section{PN-fluoxetine treatment leads to blunted dopaminergic activation during sucrose consumption}

To further investigate how the dopaminergic system is affected by $\mathrm{PN}$-fluoxetine treatment, fiber photometry was conducted using GAMCP6. GCAMP6 is a genetically encoded protein in which conformational transformation in the presence of calcium produces evoked fluorescence transients with high temporal resolution (Chen et al., 2013). Using GCAMP6 and fiber-photometry (Resendez and Stuber, 2015), bulk measurements of calciumdependent activity in specific cell populations in brain regions of interest can be obtained. This technique was used to assess changes in dopaminergic activity during sucrose consumption in our PN-fluoxetine treatment model. Dat ${ }^{\mathrm{IRES}-\mathrm{Cre} /+} ; \mathrm{GCAMP}^{\mathrm{fl} / \mathrm{fl}}$ mice were injected with saline or fluoxetine from P2 to P11. In adulthood, the mice were connected to the fiber-photometry recording setup, with the probes targeting the VTA, and their licks were recorded using Anymaze and time-stamped onto the photometry recording (Fig. 5A,B). To confirm the specificity of GCAMP6 expression in dopamine cells, two adult Dat ${ }^{\mathrm{IRES}-\mathrm{Cre} /+}$; GCAMP $6^{\mathrm{fl} / \mathrm{fl}}$ animals were processed for double-label immunofluorescence. Sampling of 1443 GCAMP6 positive cells in the VTA showed that 95\% expressed detectable TH-immunolabeling, and $100 \%$ of TH-positive cells had detectable GCAMP6 expression (Fig. 5C). We calculated the fluorescence response of VTA-dopaminergic cells by normalizing the fluorescence level $500 \mathrm{~ms}$ after the first lick to the fluorescence level $500 \mathrm{~ms}$ before the first lick. There was no difference in the latency to drink between groups $\left(t_{(16)}=0.3031, p=0.76\right)$. We observed that the increase in fluorescence was significantly lower in PN-fluoxetine-treated animals than in PN-saline-treated mice $\left(t_{(16)}=\right.$ 
2.120, $p=0.05$; Fig. $5 D-F)$, pointing to a reduced response of the dopaminergic system.

\section{Motivational deficits in PN-fluoxetine-treated mice can be rescued by adult administration of bupropion but not fluoxetine}

Next, we tested whether we could rescue the motivation deficits observed in the PN-fluoxetine-treated animals by manipulating the dopaminergic or serotonergic systems. Mice were injected with saline or fluoxetine from P2 to P11 and were trained in operant conditioning to nose-poke for sucrose at adulthood. One hour before the PR sessions, mice were injected with either saline, fluoxetine or bupropion. Each mouse was tested with the three treatments administered with an interval of 72 $\mathrm{h}$, in counterbalanced order (Fig. 6A).

An overall effect of postnatal treatment was observed; PNfluoxetine mice showed a significantly lower break point than PN-saline-treated mice $\left(F_{(1,41)}=6.014, p=0.02\right.$; Fig. $\left.6 B\right)$. Interestingly, while bupropion significantly increased the break point in both PN-saline (Sidak's multiple comparisons test: adjusted $p=0.02$ ) and PN-fluoxetine (Sidak's multiple comparisons test: adjusted $p=0.001$ ), the break point did not increase in mice treated with fluoxetine in adulthood. Notably, PN-fluoxetine mice treated with bupropion in adulthood reached performance levels similar to PN-saline control mice treated with saline in adulthood (Fig. 6B).

\section{Discussion}

Our novel results show that developmental exposure to the SSRI fluoxetine has long-term effects on a well-established index of effort-related motivation. Our findings demonstrate that $\mathrm{PN}$-fluoxetine treatment leads to behavioral deficits in an operant conditioning task, specifically when the effort-demand increases. PN-fluoxetine treatment also leads to a blunted dopaminergic response to an amphetamine challenge and a positive reinforcer (sucrose solution). Furthermore, we show that PN-fluoxetine motivation-related deficits can be rescued in the adult by increasing dopaminergic activity using bupropion, a norepinephrine-dopamine reuptake inhibitor.

\section{Dopamine and effort-related motivation}

An extensive literature from Salamone's laboratory, the majority done on rats, has implicated dopamine levels in effort-related motivation (Salamone et al., 2016a). For instance, the norepinephrine-dopamine-transporter-inhibitor bupropion has been shown to increase performance in high effort tasks (Randall et al., 2014) while the dopamine D2 antagonist haloperidol shifts choice from a preferred food to a less preferred alternative in an effortful context (Yang et al., 2020). Our current results show the same pattern in mice using a PR: bupropion administration increased the break point, while haloperidol decreased it.

In our PN-model, basal levels of dopamine are similar between $\mathrm{PN}$-saline and $\mathrm{PN}$-fluoxetine animals, as measured by microdialysis. Interestingly, we only observed differences in dopamine levels/activity between groups when we performed an amphetamine challenge or in response to a reward. Consistent with the role of dopamine disruption leading to effort-related motivational deficits, we found an association between a disruption in dopaminergic activation in response to a sucrose reward in $\mathrm{PN}$-fluoxetine-treated mice with a reduction in performance in a PR schedule of reinforcement. These deficits were not observed in low effort schedules (FR1 and FR5). Several studies

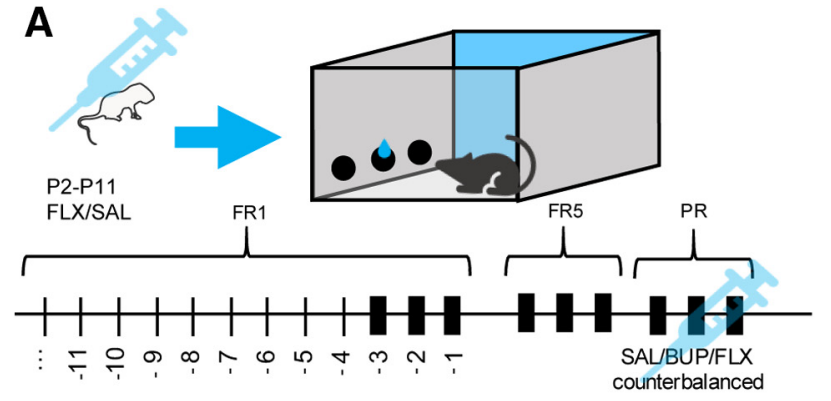

B

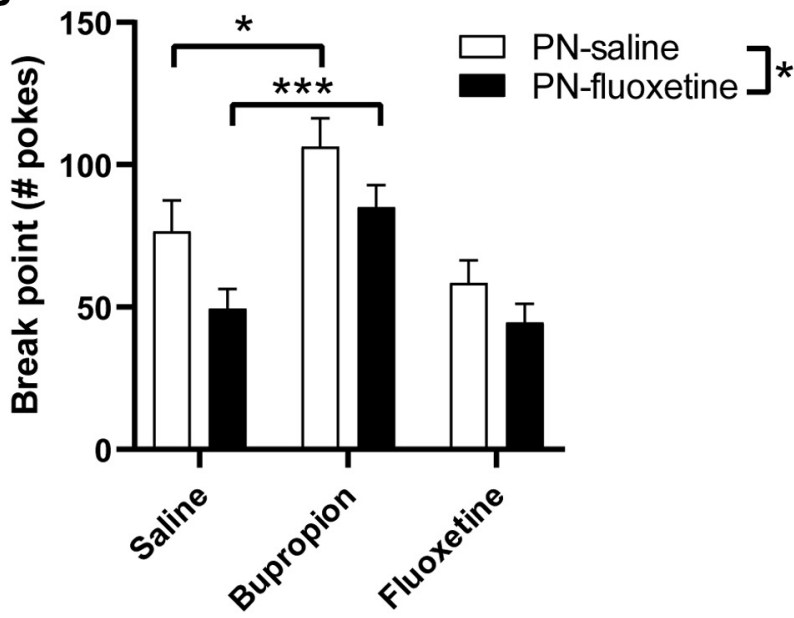

Adult treatment

Figure 6. PN-fluoxetine impairment in effort-related motivation can be rescued in adulthood by bupropion. $A$, Experimental design. PN-treated mice were trained on a FR1 schedule of reinforcement until reaching criteria. They were then trained for an additional $3 \mathrm{~d}$ on the FR5 schedule. The following day, they were tested on the PR $1 \mathrm{~h}$ after receiving an injection of either saline (SAL), bupropion (BUP; dopamine-reuptake-inhibitor), or fluoxetine (FLX; SSRI) in a counterbalanced design. $\boldsymbol{B}$, Break point on PR schedule after adult treatment $\left(n_{\mathrm{PN}-\text { saline }}=19, n_{\mathrm{PN} \text {-fluoxetine }}=24\right)$. Data are expressed as the mean $\pm \mathrm{SEM} ; * p<0.05$, $* * * p<0.001$

have shown a link between dopamine depletion and deficits in more effortful instrumental tasks (McCullough et al., 1993; Aberman et al., 1998; Salamone et al., 2001; Ishiwari et al., 2004). The greater the effort required by the task, the stronger the effect of dopamine depletion. Dopamine depletion only slightly impairs performance in an operant FR1 task, moderately degrades performance in moderate demand schedules (FR5), and severely impairs performance at higher ratios (McCullough et al., 1993; Aberman et al., 1998; Salamone et al., 2001; Ishiwari et al., 2004).

In a review of the behavioral effects of perinatal SSRI exposure, the analysis of ingestive and reward behavior showed no differences between controls and animals treated with fluoxetine perinatally (Ramsteijn et al., 2020). Most of these papers refer to ingestive behavior (food consumption; 13 out of the 24 experiments analyzed). This agrees with our data in which rewards earned in low effort tasks (FR1 and FR5) did not differ, suggesting that there are no inherent differences in intake and satiety. The difference was only observed when the component of effort was added. In the study by (Forcelli and Heinrichs, 2008), the authors performed a conditioned-place-preference experiment to test the hedonic value of cocaine in prenatally fluoxetine treated rats. They found an increase in time spent in the cocainepaired location in PN-fluoxetine mice. However, conditionedplace-preference tests can answer the question of whether an 
animal prefers a particular reward (liking) but do not provide information about how much the animal is willing to work (wanting) for that reward (Berridge et al., 2009; Berridge and Robinson, 2016). On the cocaine self-administration test, rats were tested using an FR1 schedule $(0.375 \mathrm{mg} / \mathrm{kg} /$ injection in 0.1 $\mathrm{ml} /$ injection saline delivered over $4 \mathrm{~s}$ ), with no difference in performance on this schedule. This schedule also does not address the question of effort (Forcelli and Heinrichs, 2008). These studies support our data of no difference in sucrose intake in low effort schedules with a difference in performance revealed when the effort required to obtain the reward was increased.

\section{Early-life SSRI exposure}

While more research in humans is still needed, discontinuation of antidepressant treatment during pregnancy is often not possible given the potentially severe consequences of untreated prenatal maternal depression, to both the mother and the neonate (Jablensky et al., 2005; Pearson et al., 2013; Jarde et al., 2016; Aftab and Shah, 2017). Some SSRIs are a relatively safe and effective treatment option for depression during pregnancy and breastfeeding (Carr and Lucki, 2011; Reefhuis et al., 2015). However, more research needs to be conducted on the outcomes of exposed children.

In rodents, exposure to the prototypical SSRI fluoxetine during development has been shown to cause decreased exploration, decreased social interaction, increased floating in the forcedswim-test, and anxiety-related behavioral phenotypes (Ansorge et al., 2004, 2008; Sarkar et al., 2014). However, these studies, like ours, used non-depressed dams. It is intriguing that in some studies using animal models of maternal depression, SSRI administration during pregnancy rescued the behavior and the disruption of brain development caused by maternal depression (Salari et al., 2016; Velasquez et al., 2019).

Our study found a reduction in motivation and dopaminergic activation in mice exposed to fluoxetine during early life. Future work should examine how PN-fluoxetine affects aggression, risktaking behavior, and drug seeking. We have previously shown that exposure to fluoxetine during adolescence reduces adult aggression ( $\mathrm{Yu}$ et al., 2014). With respect to drug addiction, reduced dopamine activation caused by $\mathrm{PN}$-fluoxetine might cause lower vulnerability to addiction, as mesolimbic dopaminergic pathway lesions have been shown to reduce heroin reinforcing effects (Spyraki et al., 1983). Alternatively, imaging studies show that reduced dopamine release in the striatum is correlated with increased addiction to several substances (Martinez et al., 2012).

To try to rescue the changes in motivation we observed in PN-fluoxetine animals, we tested two antidepressants with different targets, fluoxetine, an SSRI, and bupropion, a norepinephrine, dopamine reuptake inhibitor (Horst and Preskorn, 1998). Constitutive knock-out of the serotonergic transporter (SERT$\mathrm{KO}$ ) leads to similar adult behavioral changes as early-life fluoxetine exposure (Ansorge et al., 2004). However, in SERT-KO mice, increased extracellular serotonin in the adult (Mathews et al., 2004) does not rescue the phenotype induced by fluoxetine exposure during development (Ansorge et al., 2004). This suggests that SSRIs may not be sufficient to rescue behavioral modifications in the adult when high serotonin levels are disrupted in early brain development. We have recently shown that PN-fluoxetine treatment leads to reduced exploration in adulthood. This reduced exploration could be rescued by optogenetic activation of dopaminergic cells but not by activation of serotonergic ones (Cunha et al., 2020). Consistently, the current results show that the lower motivation levels in PN-fluoxetine-treated mice in adulthood can be rescued by treatment with bupropion, but not with fluoxetine. While our data suggest that early-life fluoxetine treatment affects dopaminergic function and that bupropion may revert these deficits possibly by also acting on the dopaminergic system, bupropion may revert the reduction in motivation by its action on norepinephrine (Nomikos et al., 1989, 1992; Horst and Preskorn, 1998; Li et al., 2002). These results may have important implications for therapeutic interventions in motivational deficits observed in depressed patients, suggesting that in some cases, interventions targeting the dopaminergic/ norepinephrine systems should be considered.

\section{References}

Aberman JE, Ward SJ, Salamone JD (1998) Effects of dopamine antagonists and accumbens dopamine depletions on time-constrained progressiveratio performance. Pharmacol Biochem Behav 61:341-348.

Aftab A, Shah AA (2017) Behavioral emergencies: special considerations in the pregnant patient. Psychiatr Clin North Am 40:435-448.

Altieri SC, Yang H, O'Brien HJ, Redwine HM, Senturk D, Hensler JG, Andrews AM (2015) Perinatal vs genetic programming of serotonin states associated with anxiety. Neuropsychopharmacology 40:1456-1470.

Ansorge MS, Zhou M, Lira A, Hen R, Gingrich JA (2004) Early-life blockade of the 5-HT transporter alters emotional behavior in adult mice. Science 306:879-881.

Ansorge MS, Morelli E, Gingrich JA (2008) Inhibition of serotonin but not norepinephrine transport during development produces delayed, persistent perturbations of emotional behaviors in mice. J Neurosci 28:199207.

Bäckman CM, Malik N, Zhang Y, Shan L, Grinberg A, Hoffer BJ, Westphal $\mathrm{H}$, Tomac AC (2006) Characterization of a mouse strain expressing Cre recombinase from the 3 ' untranslated region of the dopamine transporter locus. Genesis 44:383-390.

Balla A, Dong B, Shilpa BM, Vemuri K, Makriyannis A, Pandey SC, Sershen H, Suckow RF, Vinod KY (2018) Cannabinoid-1 receptor neutral antagonist reduces binge-like alcohol consumption and alcohol-induced accumbal dopaminergic signaling. Neuropharmacology 131:200-208.

Beier KT, Steinberg EE, DeLoach KE, Xie S, Miyamichi K, Schwarz L, Gao XJ, Kremer EJ, Malenka RC, Luo L (2015) Circuit architecture of VTA dopamine neurons revealed by systematic input-output mapping. Cell 162:622-634.

Berridge KC, Robinson TE (2016) Liking, wanting, and the incentive-sensitization theory of addiction. Am Psychol 71:670-679.

Berridge KC, Robinson TE, Aldridge JW (2009) Dissecting components of reward: 'liking', 'wanting', and learning. Curr Opin Pharmacol 9:65-73.

Carr GV, Lucki I (2011) The role of serotonin receptor subtypes in treating depression: a review of animal studies. Psychopharmacology (Berl) 213:265-287.

Chen TW, Wardill TJ, Sun Y, Pulver SR, Renninger SL, Baohan A, Schreiter ER, Kerr RA, Orger MB, Jayaraman V, Looger LL, Svoboda K, Kim DS (2013) Ultrasensitive fluorescent proteins for imaging neuronal activity. Nature 499:295-300.

Cooper WO, Willy ME, Pont SJ, Ray WA (2007) Increasing use of antidepressants in pregnancy. Am J Obstet Gynecol 196:e541-e545.

Correa M, Pardo M, Bayarri P, López-Cruz L, San Miguel N, Valverde O, Ledent C, Salamone JD (2016) Choosing voluntary exercise over sucrose consumption depends upon dopamine transmission: effects of haloperidol in wild type and adenosine AKO mice. Psychopharmacology 233:393-404.

Cunha C, Smiley JF, Chuhma N, Shah R, Bleiwas C, Menezes EC, Seal RP, Edwards RH, Rayport S, Ansorge MS, Castellanos FX, Teixeira CM. (2020) Perinatal interference with the serotonergic system affects VTA function in the adult via glutamate co-transmission. Mol Psychiatry. Advance online publication. Retrieved May 12, 2020. doi: 10.1038/ s41380-020-0763-z.

Devarakonda K, Nguyen KP, Kravitz AV (2016) ROBucket: a low cost operant chamber based on the Arduino microcontroller. Behav Res Methods 48:503-509. 
Forcelli PA, Heinrichs SC (2008) Teratogenic effects of maternal antidepressant exposure on neural substrates of drug-seeking behavior in offspring. Addict Biol 13:52-62.

Goeden N, Velasquez J, Arnold KA, Chan Y, Lund BT, Anderson GM, Bonnin A (2016) Maternal inflammation disrupts fetal neurodevelopment via increased placental output of serotonin to the fetal brain. J Neurosci 36:6041-6049.

Gundersen HJG, Bagger P, Bendtsen TF, Evans SM, Korbo L, Marcussen N, Moller A, Nielesen K, Nyengaard JR, Pakkenberg B, Sorensen FB, Vesterby A, West MJ (1988) The new stereological tools: Dissector, fractionator, nucleator and point sampled intercepts and their use in pathological research and diagnosis. Acta Pathol Microbiol Immunol Scan 96:857-881.

Hohmann CF, Hamon R, Batshaw ML, Coyle JT (1988) Transient postnatal elevation of serotonin levels in mouse neocortex. Brain Res 471:163-166.

Homberg JR, Schubert D, Gaspar P (2010) New perspectives on the neurodevelopmental effects of SSRIs. Trends Pharmacol Sci 31:60-65.

Horst WD, Preskorn SH (1998) Mechanisms of action and clinical characteristics of three atypical antidepressants: venlafaxine, nefazodone, bupropion. J Affect Disord 51:237-254.

Huybrechts KF, Palmsten K, Mogun H, Kowal M, Avorn J, Setoguchi-Iwata S, Hernández-Díaz S (2013) National trends in antidepressant medication treatment among publicly insured pregnant women. General hospital psychiatry 35:265-271.

Ishiwari K, Weber SM, Mingote S, Correa M, Salamone JD (2004) Accumbens dopamine and the regulation of effort in food-seeking behavior: modulation of work output by different ratio or force requirements. Behav Brain Res 151:83-91.

Jablensky AV, Morgan V, Zubrick SR, Bower C, Yellachich LA (2005) Pregnancy, delivery, and neonatal complications in a population cohort of women with schizophrenia and major affective disorders. Am J Psychiatry 162:79-91.

Jarde A, Morais M, Kingston D, Giallo R, MacQueen GM, Giglia L, Beyene J, Wang Y, McDonald SD (2016) Neonatal outcomes in women with untreated antenatal depression compared With women without depression: a systematic review and meta-analysis. JAMA Psychiatry 73:826837.

Kalsbeek A, Voorn P, Buijs RM, Pool CW, Uylings HB (1988) Development of the dopaminergic innervation in the prefrontal cortex of the rat. J Comp Neurol 269:58-72.

Kalueff AV, Fox MA, Gallagher PS, Murphy DL (2007) Hypolocomotion, anxiety and serotonin syndrome-like behavior contribute to the complex phenotype of serotonin transporter knockout mice. Genes Brain Behav 6:389-400.

Kim CK, Yang SJ, Pichamoorthy N, Young NP, Kauvar I, Jennings JH, Lerner TN, Berndt A, Lee SY, Ramakrishnan C, Davidson TJ, Inoue M, Bito H, Deisseroth K (2016) Simultaneous fast measurement of circuit dynamics at multiple sites across the mammalian brain. Nat Methods 13:325-328.

Lauder JM, Bloom FE (1974) Ontogeny of monoamine neurons in the locus coeruleus, Raphe nuclei and substantia nigra of the rat. I. Cell differentiation. J Comp Neurol 155:469-481.

Li SX, Perry KW, Wong DT (2002) Influence of fluoxetine on the ability of bupropion to modulate extracellular dopamine and norepinephrine concentrations in three mesocorticolimbic areas of rats. Neuropharmacology 42:181-190.

Lidov HG, Molliver ME (1982a) Immunohistochemical study of the development of serotonergic neurons in the rat CNS. Brain Res Bull 9:559-604.

Lidov HG, Molliver ME (1982b) An immunohistochemical study of serotonin neuron development in the rat: ascending pathways and terminal fields. Brain Res Bull 8:389-430.

Madisen L, Garner AR, Shimaoka D, Chuong AS, Klapoetke NC, Li L, van der Bourg A, Niino Y, Egolf L, Monetti C, Gu H, Mills M, Cheng A, Tasic B, Nguyen TN, Sunkin SM, Benucci A, Nagy A, Miyawaki A, Helmchen F, et al. (2015) Transgenic mice for intersectional targeting of neural sensors and effectors with high specificity and performance. Neuron 85:942-958.

Malm H, Brown AS, Gissler M, Gyllenberg D, Hinkka-Yli-Salomäki S, McKeague IW, Weissman M, Wickramaratne P, Artama M, Gingrich JA, Sourander A (2016) Gestational exposure to selective serotonin reuptake inhibitors and offspring psychiatric disorders: a national register-based study. J Am Acad Child Adolesc Psychiatry 55:359-366.
Martinez D, Saccone PA, Liu F, Slifstein M, Orlowska D, Grassetti A, Cook S, Broft A, Van Heertum R, Comer SD (2012) Deficits in dopamine D(2) receptors and presynaptic dopamine in heroin dependence: commonalities and differences with other types of addiction. Biol Psychiatry 71:192-198.

Mathews TA, Fedele DE, Coppelli FM, Avila AM, Murphy DL, Andrews AM (2004) Gene dose-dependent alterations in extraneuronal serotonin but not dopamine in mice with reduced serotonin transporter expression. J Neurosci Methods 140:169-181.

McCullough LD, Cousins MS, Salamone JD (1993) The role of nucleus accumbens dopamine in responding on a continuous reinforcement operant schedule: a neurochemical and behavioral study. Pharmacol Biochem Behav 46:581-586.

Murphy DL, Fox MA, Timpano KR, Moya PR, Ren-Patterson R, Andrews AM, Holmes A, Lesch KP, Wendland JR (2008) How the serotonin story is being rewritten by new gene-based discoveries principally related to SLC6A4, the serotonin transporter gene, which functions to influence all cellular serotonin systems. Neuropharmacology 55:932-960.

Nomikos GG, Damsma G, Wenkstern D, Fibiger HC (1989) Acute effects of bupropion on extracellular dopamine concentrations in rat striatum and nucleus accumbens studied by in vivo microdialysis. Neuropsychopharmacology 2:273-279.

Nomikos GG, Damsma G, Wenkstern D, Fibiger HC (1992) Effects of chronic bupropion on interstitial concentrations of dopamine in rat nucleus accumbens and striatum. Neuropsychopharmacology 7:7-14.

Olson L, Seiger A (1972) Early prenatal ontogeny of central monoamine neurons in the rat: fluorescence histochemical observations. Z Anat Entwicklungsgesch 137:301-316.

Papaioannou A, Dafni U, Alikaridis F, Bolaris S, Stylianopoulou F (2002) Effects of neonatal handling on basal and stress-induced monoamine levels in the male and female rat brain. Neuroscience 114:195-206.

Pearson RM, Evans J, Kounali D, Lewis G, Heron J, Ramchandani PG, O'Connor TG, Stein A (2013) Maternal depression during pregnancy and the postnatal period: risks and possible mechanisms for offspring depression at age 18 years. JAMA Psychiatry 70:1312-1319.

Raineki C, Sarro E, Rincón-Cortés M, Perry R, Boggs J, Holman CJ, Wilson DA, Sullivan RM (2015) Paradoxical neurobehavioral rescue by memories of early-life abuse: the safety signal value of odors learned during abusive attachment. Neuropsychopharmacology 40:906-914.

Ramsteijn AS, Van de Wijer L, Rando J, van Luijk J, Homberg JR, Olivier JDA (2020) Perinatal selective serotonin reuptake inhibitor exposure and behavioral outcomes: a systematic review and meta-analyses of animal studies. Neurosci Biobehav Rev 114:53-69.

Randall PA, Pardo M, Nunes EJ, López CL, Vemuri VK, Makriyannis A, Baqi Y, Müller CE, Correa M, Salamone JD (2012) Dopaminergic modulation of effort-related choice behavior as assessed by a progressive ratio chow feeding choice task: pharmacological studies and the role of individual differences. PLoS One 7:e47934.

Randall PA, Lee CA, Podurgiel SJ, Hart E, Yohn SE, Jones M, Rowland M, López-Cruz L, Correa M, Salamone JD (2014) Bupropion increases selection of high effort activity in rats tested on a progressive ratio/chow feeding choice procedure: implications for treatment of effort-related motivational symptoms. Int J Neuropsychopharmacol 18:pyu017.

Rebello TJ, Yu Q, Goodfellow NM, Caffrey Cagliostro MK, Teissier A, Morelli E, Demireva EY, Chemiakine A, Rosoklija GB, Dwork AJ, Lambe EK, Gingrich JA, Ansorge MS (2014) Postnatal day 2 to 11 constitutes a 5-HT-sensitive period impacting adult mPFC function. J Neurosci 34:12379-12393.

Reefhuis J, Devine O, Friedman JM, Louik C, Honein MA; National Birth Defects Prevention Study (2015) Specific SSRIs and birth defects: Bayesian analysis to interpret new data in the context of previous reports. BMJ 351:h3190

Resendez SL, Stuber GD (2015) In vivo calcium imaging to illuminate neurocircuit activity dynamics underlying naturalistic behavior. Neuropsychopharmacology 40:238-239.

Rincón-Cortés M, Barr GA, Mouly AM, Shionoya K, Nuñez BS, Sullivan RM (2015) Enduring good memories of infant trauma: rescue of adult neurobehavioral deficits via amygdala serotonin and corticosterone interaction. Proc Natl Acad Sci USA 112:881-886.

Robinson MJ, Fischer AM, Ahuja A, Lesser EN, Maniates H (2016) Roles of "wanting" and "liking" in motivating behavior: gambling, food, and drug addictions. Curr Top Behav Neurosci 27:105-136. 
Salamone JD, Wisniecki A, Carlson BB, Correa M (2001) Nucleus accumbens dopamine depletions make animals highly sensitive to high fixed ratio requirements but do not impair primary food reinforcement. Neuroscience 105:863-870.

Salamone JD, Yohn SE, López-Cruz L, San Miguel N, Correa M (2016a) Activational and effort-related aspects of motivation: neural mechanisms and implications for psychopathology. Brain 139:1325-1347.

Salamone JD, Pardo M, Yohn SE, López-Cruz L, SanMiguel N, Correa M (2016b) Mesolimbic dopamine and the regulation of motivated behavior. Curr Top Behav Neurosci 27:231-257.

Salari AA, Fatehi-Gharehlar L, Motayagheni N, Homberg JR (2016) Fluoxetine normalizes the effects of prenatal maternal stress on depression- and anxiety-like behaviors in mouse dams and male offspring. Behav Brain Res 311:354-367.

Sarkar A, Chachra P, Vaidya VA (2014) Postnatal fluoxetine-evoked anxiety is prevented by concomitant $5-\mathrm{HT} 2 \mathrm{~A} / \mathrm{C}$ receptor blockade and mimicked by postnatal 5-HT2A/C receptor stimulation. Biol Psychiatry 76:858-868.

Serfaty CA, Oliveira-Silva P, Faria Melibeu Ada C, Campello-Costa P (2008) Nutritional tryptophan restriction and the role of serotonin in development and plasticity of central visual connections. Neuroimmunomodulation 15:170-175.

Sershen H, Hashim A, Lajtha A (2010) Differences between nicotine and cocaine-induced conditioned place preferences. Brain Res Bull 81:120-124.

Shen HW, Hagino Y, Kobayashi H, Shinohara-Tanaka K, Ikeda K, Yamamoto H, Yamamoto T, Lesch KP, Murphy DL, Hall FS, Uhl GR, Sora I (2004) Regional differences in extracellular dopamine and serotonin assessed by in vivo microdialysis in mice lacking dopamine and/or serotonin transporters. Neuropsychopharmacology 29:1790-1799.
Singal D, Chateau D, Struck S, Lee JB, Dahl M, Derksen S, Katz LY, Ruth C, Hanlon-Dearman A, Brownell M (2020) In utero antidepressants and neurodevelopmental outcomes in kindergarteners. Pediatrics 145: e20191157.

Spyraki C, Fibiger HC, Phillips AG (1983) Attenuation of heroin reward in rats by disruption of the mesolimbic dopamine system. Psychopharmacology (Berl) 79:278-283.

Suri D, Teixeira CM, Cagliostro MKC, Mahadevia D, Ansorge MS (2015) Monoamine-sensitive developmental periods impacting adult emotional and cognitive behaviors. Neuropsychopharmacology 40:88-112.

Velasquez JC, Zhao Q, Chan Y, Galindo LCM, Simasotchi C, Wu D, Hou Z Herod SM, Oberlander TF, Gil S, Fournier T, Burd I, Andrews AM, Bonnin A (2019) In utero exposure to citalopram mitigates maternal stress effects on fetal brain development. ACS Chem Neurosci 10:3307-3317.

Weinstock M (2015) Changes induced by prenatal stress in behavior and brain morphology: can they be prevented or reversed? In: Perinatal programming of neurodevelopment (Antonelli MC, ed), pp 3-25. New York: Springer New York.

Xu Y, Sari Y, Zhou FC (2004) Selective serotonin reuptake inhibitor disrupts organization of thalamocortical somatosensory barrels during development. Brain Res Dev Brain Res 150:151-161.

Yang JH, Presby RE, Jarvie AA, Rotolo RA, Fitch RH, Correa M, Salamone JD (2020) Pharmacological studies of effort-related decision making using mouse touchscreen procedures: effects of dopamine antagonism do not resemble reinforcer devaluation by removal of food restriction. Psychopharmacology (Berl) 237:33-43.

Yu Q, Teixeira CM, Mahadevia D, Huang Y, Balsam D, Mann JJ, Gingrich JA, Ansorge MS (2014) Dopamine and serotonin signaling during two sensitive developmental periods differentially impact adult aggressive and affective behaviors in mice. Mol Psychiatry 19:688-698. 